\title{
Rescue and Regrowth of Sensory Nerves Following Deafferentation by Neurotrophic Factors
}

\author{
R. A. ALTSCHULER, ${ }^{a, b, e}$ Y. CHO, ${ }^{a, b}$ J. YLIKOSKI, ${ }^{c}$ U. PIRVOLA, ${ }^{c}$ \\ E. MAGAL, ${ }^{d}$ AND J. M. MILLER ${ }^{a}$ \\ ${ }^{a}$ Kresge Hearing Research Institute, University of Michigan, 1301 East Ann Street, Ann \\ Arbor, Michigan 48109-0506, USA \\ ${ }^{b}$ Department of Anatomy and Cell Biology, University of Michigan, Ann Arbor, Michigan \\ 48109-0506, USA \\ 'Institute of Biotechnology, University of Helsinki, P.O. Box 56, Viikinkaari 9, FIN-0014 \\ Helsinki, Finland \\ ${ }^{d}$ Department of Neurobiology, Amgen Inc., Thousand Oaks, California 91320, USA
}

\begin{abstract}
Trauma and loss of cochlear inner hair cells causes a series of events that result first in the retraction of the peripheral processes of the auditory nerve, scar formation in the organ of Corti, and over the course of weeks to months (depending on the species) the loss of auditory nerve cell bodies (spiral ganglion cells). Neurotrophic factors play an important role in the mature nervous system as survival factors for maintenance and protection and also can play a role in regrowth. Studies in the cochlea now show that application of exogenous neurotrophic factors can enhance survival of spiral ganglion cells after deafness and induce regrowth of peripheral processes, perhaps by replacing lost endogenous factors. Combinations of factors may be most effective for achieving greatest survival and regrowth. Our studies find that brain-derived neurotrophic factor (BDNF) and glial-line-derived neurotrophic factor (GDNF) are very effective at enhancing spiral ganglion cell survival following deafness from ototoxic drugs or noise. It has also been found that BDNF plus fibroblast growth factor (FGF) is very effective at inducing process regrowth. Electrical stimulation also acts to enhance spiral ganglion cell survival, and the combination of electrical stimulation and neurotrophic factors could prove a most effective intervention.
\end{abstract}

Deafness with the loss of inner hair cells (IHC) results in progressive pathophysiological changes that can end in the degeneration of most auditory nerve neurons. It is now possible to consider these events in the broader context of antiapoptotic survival factors in the peripheral and central nervous system. One possible consequence of the loss of sensory or neural elements can be a loss of support or survival factors necessary for the target cells. The absence of these factors can cause changes ranging from the downregulation of normal function to the initiation of biochemical cascades leading to cell death through apoptosis or necrosis. The impact of deafferentation on

${ }^{e}$ To whom correspondence may be addressed. Phone: 734/763-0060; fax: 734/764-0014; email: shuler@umich.edu 
the target cells appears to depend upon the extent to which other supporting inputs (and their survival factors) are available, and with the loss of an exclusive input, target cells typically die (for review, see reference 1).

For the auditory nerve, the cell death that normally follows complete loss of sensory cells ${ }^{2-5}$ can be prevented by chronic direct electrical activation of the auditory nerve with cochlear prostheses. ${ }^{6-8}$ Moreover, the stimulation is effective even when provided for only brief (30 min) intermittent periods (once per week), if at sufficiently high intensities. ${ }^{9}$ These intensities are sufficient to express the intermediate-early gene $\mathrm{C}$-fos ${ }^{10}$ which, in turn, can initiate transcription of antiapoptotic genes and pathways. This activity can also upregulate products that act in an autocrine manner to protect the nerve from death. Additionally, when propagated action potentials are blocked by tetrodotoxin in models, the auditory nerve cannot be rescued from cell death. ${ }^{9}$

It is now clear that neurotrophic factors function not only as growth, survival, proliferative, and differentiation factors during development but also in maintaining the mature nervous system, particularly the mature system under stress. ${ }^{1}$ The specific mechanism of their action is not clear, but it involves receptor tyrosine kinase-activated intracellular cascades, probably involving Ras-MAP kinase and/or PI-3 kinase. These pathways might play a role in intracellular ion homeostasis, particularly in the maintenance of intracellular $\mathrm{Ca}^{2+}$ concentration at an appropriate level, and in the regulation of antiapoptotic factors, such as Bcl-2. ${ }^{11}$

Many neurotrophic factors and their receptors have been identified in the mammalian cochlea. IHCs are a potential source of neurotrophic factors to the auditory nerve. Expression of neurotrophin 3 (NT-3) $)^{12,13}$ and glial cell line-derived neurotrophic factor $(\mathrm{GDNF})^{14}$ have been identified in hair cells. A neurotrophic factor might also be released from the auditory nerve and act in an autocrine fashion. Brainderived neurotrophic factor (BDNF) ${ }^{15} \mathrm{NT}-3,{ }^{12} \mathrm{GDNF},{ }^{14}$ and acidic fibroblast growth factor $(\mathrm{aFGF})^{16}$ are all expressed in the auditory nerve. Hegarty and colleagues ${ }^{15}$ have provided in vitro evidence for a spiral ganglion cell (SGC) autocrine loop of neurotrophic factors induced by depolarization. FGF has been demonstrated to be upregulated under conditions of oxidative stress. ${ }^{17}$ The receptors for BDNF and NT-3 (trk b and trk c, respectively), as well as the GDNFR- $\alpha$ component of the GDNF receptor complex, ${ }^{14}$ have been identified in the auditory nerve, ${ }^{12}$ although evidence for c-Ret (the membrane-spanning component of the receptor complex) was not found. The receptor for FGF has been identified in supporting cells. ${ }^{17}$

In vitro studies have demonstrated enhanced survival of SGC with a variety of neurotrophic factors, including BDNF and NT-3 and an interaction of these factors with potassium-induced depolarization or leukemia inhibitory factor. ${ }^{15,18}$ The development of chronic local delivery systems, such as miniosmotic pumps and microcannulation of the inner ear ${ }^{19}$ and viral vectors, ${ }^{20}$ have made it possible to evaluate the in vivo efficacy of these neurotrophic factors. Two deafness models have been evaluated in in vivo animal studies. One is an ototoxicity model, using a single aminoglycoside or a combination of an aminoglycoside and ethacrynic acid. In this model, $\mathrm{BDNF},{ }^{21,22} \mathrm{NT}-3,{ }^{22,23}$ nerve growth factor (NGF), ${ }^{24,25}$ and $\mathrm{GDNF}^{26}$ have been shown to enhance SGC survival after deafness. In our studies ${ }^{9,26}$ we found that BDNF and GDNF are the most effective and are comparably effective, either singly or combined with other neurotrophic factors (FIG. 1). GDNF is effective at lower dosages than 
BDNF. We found that ciliary neurotrophic factor (CNTF) and FGF are not effective in enhancing SGC survival, and that NT-3 provides only a slight improvement.

The most dramatic effect in enhancing SGC survival after deafness was with GDNF in a second deafness model, noise overstimulation. Following the broad destruction of inner IHC and outer hair cells (OHC) (essentially the upper 25\% of the basal turn of the cochlea through the entire second turn) by intense noise exposure, SGCs were rescued from cell death with the chronic, local application of a moderately high concentration of GDNF. ${ }^{14}$ In this study, eight subjects were exposed to onethird octave-band noise (4-kHz center frequency, 130-dB SPL) for $5 \mathrm{~h}$. This exposure produced an auditory brain-stem response threshold shift of $70-80 \mathrm{~dB}$ at $2,4,6,8$, and $20 \mathrm{kHz}$ and, across all subjects, the wide destruction of $\mathrm{OHC}$ and $\mathrm{IHC}$, extending from the upper $25 \%$ of the basal turn through the second turn. Three days following noise exposure, these subjects were implanted with a microcannula of the scala tympani attached to a miniosmotic pump (Alzet巴), delivering GDNF $(100-144 \mu \mathrm{g} / \mathrm{mL}$, $n=6)$ or artificial perilymph (AP, $n=2)$ for three weeks at $0.5 \mu \mathrm{L} / \mathrm{h}$. Midmodiolar sections were taken from these subjects, and SGC survival was compared in the GDNF-treated, AP-treated, and contralateral untreated ears and in 8 ears from 4 nonexposed normal subjects. SGCs were sampled from four sites, representing the upper basal turn and lower, middle, and upper second turn. No difference in SGC survival was observed between AP-treated and nontreated noise-exposed ears, hence these

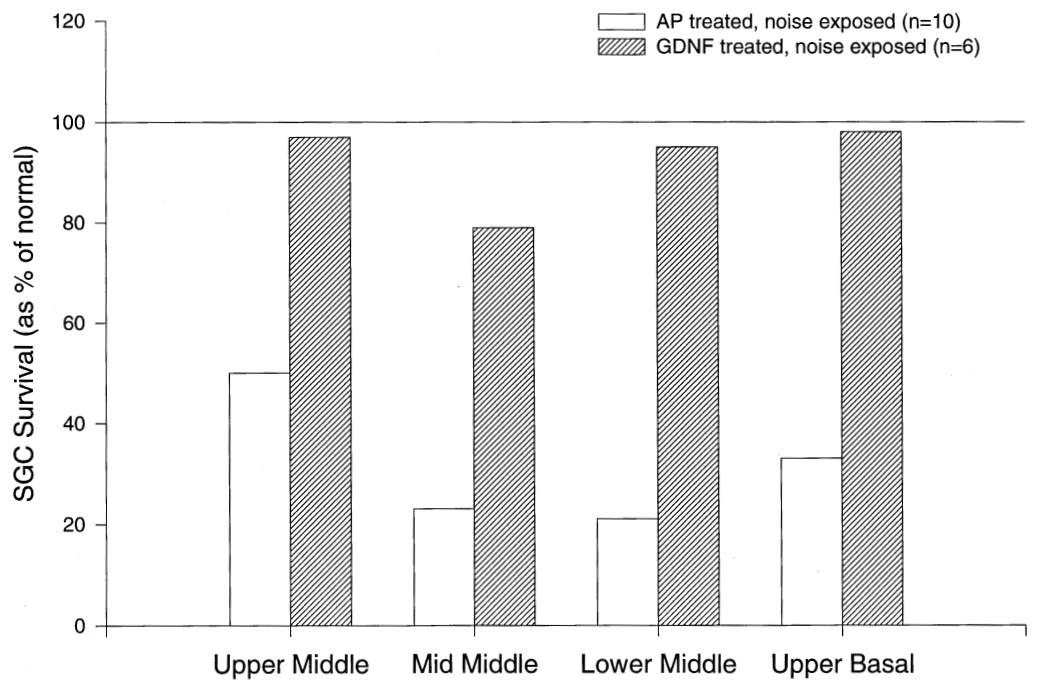

FIGURE 1. The relative efficacy of intrascalar infusion of different neurotrophic factor treatments in enhancing SGC survival in the basal turn of the guinea pig cochlear spiral, after bilateral deafness from systemic kanamcyin and ethacrynic acid. AP-artificial perilymph; BDNF - brain-derived neurotrophic factor; NT3 - neurotrophin 3; GDNF - glial cell line-derived neurotrophic factor; Cocktail—combination of BDNF, NT3, GDNF, and CNTF. In each group of animals, SGC numbers in the basal turn reference area is compared to the contralateral untreated side. The top line shows SGC number in the normal cochlea. 
groups were combined. FIGURE 2 illustrates the SGC survival in the GDNF- and nonGDNF-treated noise-exposed ears as a percent of SGCs observed in nonexposed ears. Compared to SGC survival ranging from $21 \%$ to $50 \%$ in the noise-exposed control ears, GDNF-treated ears showed survival ranges of 79 to $98 \%$ of normal. The effectiveness of GDNF in SGC preservation was remarkable in this study, but the interpretation is not unambiguous because of the potential presence of other survival factors in the remaining basal and apical organ of Corti of these subjects.

One of the initial events following IHC trauma or loss is the swelling and regression of auditory nerve peripheral processes. It has been shown that when the IHC is healthy, these processes can regrow and reconnect. ${ }^{27,28}$ After complete IHC loss, there is no regrowth to the IHC region, although Bohne and Harding ${ }^{29}$ report regrowth when there are regions with remaining IHCs. Thus, neurotrophic factors can play a role in SGC process regrowth as well as in SGC survival. Many of the studies examining neurotrophic factor enhancement of SGC survival have, indeed, reported regrowth, particularly after BDNF and/or NT-3 infusion. ${ }^{9,22,23}$ We used GAP- $43^{9}$ to identify the regrowth of auditory fibers, curving under the ossious spiral lamina into scala tympani, in ears chronically treated with BDNF $(50 \mathrm{ng} / \mathrm{mL})+\mathrm{NT}-3(50 \mathrm{ng} / \mathrm{mL})$ + GDNF (10 ng/mL) + CNTF (50 ng/mL). We are also using pan-trk receptor immunolabeling of peripheral processes to compare and contrast the efficacy of different neurotrophic factors, singly or in combination. While BDNF alone induced process regrowth, the richest and most extended labeling into the region of the previous organ of Corti was with BDNF + aFGF. aFGF alone was less effective, with few-

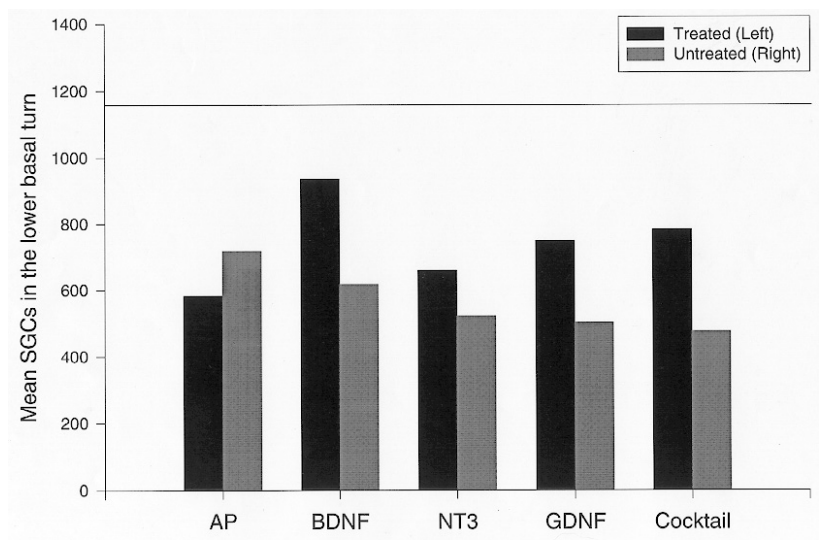

FIGURE 2. Comparison of spiral ganglion cell (SGC) survival after noise overstimulation in cochleae treated (intrascalar infusion) with glial cell line-derived neurotrophic factor (GDNF) and cochleae treated with artificial perilymph (AP). Enhanced SGC survival is seen in the treated side in three reference areas in the middle turn of the guinea pig cochlear spiral and a reference area in the upper basal turn. SGC survival is expressed as a percent of normal (line for $100 \%$ percent is shown over bars). 
er processes and less growth into the organ of Corti region. Moreover, while CNTF was least effective as a survival factor, a few processes were observed extending into the region of the organ of Corti. Clearly, the poor effect of CNTF and FGF as SGC survival factors would reduce their efficacy in inducing regrowth since they would have little effect on dead or dying SGCs. This could explain the effectiveness of the BDNF and FGF combination, with BDNF functioning both as a survival factor and for regrowth, and with FGF influencing regrowth.

There is, therefore, compelling evidence that it is possible to intervene in the deaf cochlea to enhance the survival of the auditory nerve as well as to induce regrowth of peripheral processes. This will be important in the future if and when it becomes possible to induce regeneration of cochlear hair cells, which would still need the auditory nerve to transmit auditory information centrally. Of more immediate interest, enhancement of auditory nerve survival is also essential to provide optimal performance of cochlear prostheses.

The cochlear prosthesis now provides an effective treatment for the profoundly deaf and, importantly, it is being applied with remarkable success in young children. One significant element in cochlear prosthesis success is the survival of the auditory nerve, which the prosthesis directly stimulates to send acoustic information to the brain. Yet the physiological processes associated with profound sensorineural deafness, the defining condition for implant candidacy, lead to auditory nerve cell death. The studies and results discussed previously suggest that there are effective ways to prevent this neuronal loss. Moreover, while there is no compelling clinical evidence to indicate that cochlear prostheses' benefits increase with the survival of the eighth nerve peripheral processes, there are model data and physiological evidence that this is the case. ${ }^{30-33}$ The contact of individual nerve fibers with discrete stimulation sites on a cochlear prosthesis should lead to lower thresholds, increased dynamic range of function, and greater selectivity of excitation. These features surely increase our capabilities of individualizing speech processor programs, and this should lead to greater benefits of the cochlear prosthesis.

A future generation of cochlear prosthesis might have features for neurotrophic factor delivery, such as factor delivery channels and/or biopolymer coatings to deliver factors or provide a matrix for genetically altered cells to generate them. Such factors can be provided in combination and in sequence to maintain cell survival, to initiate peripheral process-directed regrowth, and to provide a target and maintenance factor. These factors then will engineer the tissues of the inner ear to optimize the prosthesis-tissue interface and the perceptual benefits provided by a future generation of implants.

\section{ACKNOWLEDGMENTS}

This research was supported by NIH, NIDCD Program Project Grant DC DC00274 and AMGEN. We thank Alice Mitchell, Diane Prieskorn, and Peter Finger for their expert assistance in the described studies, and Nadine Brown for help in manuscript preparation. 


\section{REFERENCES}

1. Mattson, M. P. \& K. Furakawa. 1996. Programmed cell life: anti-apoptotic signaling and therapeutic strategies for neurodegenerative disorders. Restor. Neurol. Neurosci. 9: 191-205.

2. Spoendlin, H. 1975. Retrogtade degeneration of the cochlear nerve. Acta Otolaryngol. (Stockh.) 79: 266-275.

3. Ylikoski, J., J. Wersall \& B. Bjorkroth. 1974. Degeneration of neural elements in the cochlea of the guinea pig after damage to the organ of Corti by ototoxic antibiotics. Acta Otolaryngol. (Stockh.), 326 (Suppl.): 23-41.

4. Webster, M. \& D. B. Webster. 1981. Spiral ganglion neuron loss following organ of Corti loss: a quantitative study. Brain Res. 212: 17-30.

5. Jyung, R. W., J. M. Miller \& S. C. CANnON. 1989. Evaluation of eighth nerve integrity by the electrically evoked middle latency response. Otolaryngol. Head Neck Surg. 101(6): 670-682.

6. Hartshorn, D. O., J. M. Miller \& R. A. Altschuler. 1991. Protective effect of electrical stimulaiton in the deafened guinea pig cochlea. Otolaryngol. Head Neck Surg. 104: 311-319.

7. LOUSTEAU, R. J. 1987. Increased spiral ganglion survival in electrically stimulated, deafened guinea pig cocheae. Laryngoscope 97: 836-842.

8. Leake, P. A., G. T. Hradek, S. J. Rebscher, et al. 1991. Chronic intracochlear electrical stimulation induces selective survival of spiral ganglion neurons in neonatally deafened cats. Hear. Res. 54: 251-271.

9. Miller, J. M., D. Chi, P. KruszKa, et al. 1997. Neurotropins can enhance spiral ganglion cell survival after inner hair cell loss. Int. J. Dev. Neurosci. 15: 631-643.

10. Saito, H., R. A. Altschuler \& J. M. Miller. 1997. Fos-immunoreactivity expressed in the spiral ganglion and cochlear nucleus following site specific bipolar cochlear electrical stimulation (Abstr.). Association for Research in Otolaryngology.

11. DAvies, A. M. 1995. The Bcl-2 family of proteins, and the regulation of neuronal survival. Trends Neurosci. 18: 355-358.

12. Likoski, J., U. Pirvola, M. Moshnyakov, et al. 1993. Expression patterns of neurotrophins and their receptor mRNAs in the rat inner ear. Hear. Res. 65: 69-78.

13. Wheleler, E. F., M. Bothwell, L. C. Schecterson \& C. S. von Bartheld. 1994. Expression of BDNF and NT3 mRNA in hair cells of the organ of Corti: Quantitative analysis in developing rats. Hear. Res. 73: 46-56.

14. Ylikoski, J., U. Pirvola, P. Suvanto, et al. 1998. Guinea pig auditory neurons are protected by GDNF from degeneration after noise trauma. Hear. Res. In press.

15. Hegarty, J. L., A. R. Kay \& S. H. Green. 1997. Trophic support of cultured spiral ganglion neurons by depolarization exceeds and is additive with that by neurotrophins of cAMP and requires elevation of $\left[\mathrm{Ca}^{2+}\right]_{\mathrm{I}}$ within a set range. J. Neurosci. 17(6): $1859-1970$.

16. Luo, L., H. Koutnouyan, A. Baird, et al. 1993. Acidic and basic FGF mRNA in the adult and developing rat cochlea. Hear. Res. 69: 182-193.

17. Pirvola, U., Y. Cao, C. Oellig, et al. 1995. The site of action of neuronal acidic fibroblast growth factor is the organ of Corti of the rat cochlea. Proc. Natl. Acad. Sci. USA 92: 9269-9273.

18. Arzella, P. L., G. M. Clark, R.K. Sheperd, et al. 1997. LIF potentiates the NT-3-mediated survival of spiral ganglia neurones in vitro. Neuroreport 8(7): 1641-1644.

19. Brown, J. N., J. M. Miller, R. A. Altschuler, et al. 1993. Osmotic pump implants for chronic infusion of drugs into the inner ear. Hear. Res. 70: 167-172. 
20. Raphael, Y., J. C. Frisancho \& B. J. Roessler. 1996. Adenovirus-mediated gene transfer into guinea pig cochlear cells in vivo. Neurosci. Lett. 207: 137-141.

21. Staecker, H., R. Gabaizadeh, H. Federoff, et al. 1998. Brain-derived neurotrophic factor gene therapy prevents spiral ganglion degeneration after hair cell loss. Otolaryngol. Head Neck Surg. 119: 7-13.

22. Staecker, H., R. Kopke, B. Malagrange, et al. 1996. NT-3 and/or BDNF therapy prevents loss of auditory neurons following loss of hair cells. Neuroreport 7: 889-894.

23. Ernfors, P., M. L. Duan, W.M. El Shamy, et al. 1996. Protection of auditory neurons from aminoglycoside toxicity by neurotrophin-3. Nat. Med. 2(4): 463-467.

24. Schindler, R. A., H. B. Gladstone, N. Scott, et al. 1995. Enhanced preservation of the auditory nerve following cochlear perfusion with nerve growth factor. Am. J. Otol. 16(3): 304-309.

25. Shah, S. B., H. B. Gladstone, H. Williams, et al. 1995. An extended study: protective effects of nerve growth factor in neomycin-induced auditory neural degeneration. Am. J. Otol. 16(3): 310-314.

26. Altschuler, R. A., J. M. Miller, A. Mitchell, et al. 1997. GDNF enhances survival of auditory neurons following drug induced deafness. Abstr. Soc. Neurosci. 1: 619.

27. Puel, J. L., S. Saffiedine, G. D'Aldin, et al. 1995. Synaptic regeneration and functional recovery after excitotoxic injury in the guinea pig cochlea. C. R. Acad. Sci.-Ser. III, Sci. Vie 318(1): 67-75.

28. Puel, J. L., G. D'Aldin, S. SAFfiedine, et al. 1996. Excitotoxicity and plasticity of IHC-auditory nerve contributes to both temporary and permanent threshold shift. In Scientific Basis of Noise-Induced Hearing Loss, A. Axelsson, H. Borchgrevink, R. P. Hamernik, P. A. Hellstrom, D. Henderson, and R. J. Salvi, Eds.: 36-42. Thieme Medical Publishers.

29. Bohne, B. A. \& G. W. Harding. 1992. Neural regeneration in the noise-damaged chinchilla cochlea. Laryngoscope 102(6): 693-703.

30. Parkins, C. W. \& J. Colombo. 1987. Auditory-nerve single-nerve thresholds to electrical stimulation from scala tympani electrodes. Hear. Res. 31: 267-286.

31. Colombo, J. \& C. W. PArkins. 1987. A model of electrical excitation of the mammalian auditory nerve neuron. Hear. Res. 31: 287-312.

32. Stypulkowski, P. H. \& C. van Den Honert. 1984. Physiological properties of the electrically stimulated auditory nerve. I. Compound action potential recordings. Hear. Res. 14: 205-223.

33. Van den Honert, C. \& P. H. Stypulkowski. 1984. Physiological properties of the electrically stimulated auditory nerve. II. Single fiber recordings. Hear. Res. 14: 225-243. 